\title{
Diagnosing and prioritizing uncertainties according to their relevance for policy: The case of transgene silencing
}

\author{
Martin Paul Krayer von Krauss ${ }^{a, *}$, Matthias Kaiser ${ }^{b}$, Vibeke Almaas ${ }^{b}$, \\ Jeroen van der Sluijs ${ }^{c}$, Penny Kloprogge ${ }^{c}$ \\ ${ }^{a}$ European Centre for Environment and Health, WHO, Regional Office for Europe, Scherfigsuej 8, 2100 Copenhagen $\varnothing$, Denmark \\ ${ }^{b}$ Norwegian National Committee for Research Ethics in Science and Technology (NENT), Norway \\ ${ }^{\mathrm{C} U t r e c h t}$ University, Copernicus Institute for Sustainable Development and Innovations, the Netherlands
}

\section{A R T I C L E I N F O}

\section{Article history:}

Received 2 March 2007

Received in revised form

31 August 2007

Accepted 7 September 2007

Available online 7 November 2007

Keywords:

Uncertainty

Precaution

Policy

Transgene silencing

Risk assessment

Genetically modified organisms

Expert elicitation

\begin{abstract}
A B S T R A C T
Uncertainty often becomes problematic when science is used to support decision making in the policy process. Scientists can contribute to a more constructive approach to uncertainty by making their uncertainties transparent. In this article, an approach to systematic uncertainty diagnosis is demonstrated on the case study of transgene silencing and GMO risk assessment.

Detailed interviews were conducted with five experts on transgene silencing to obtain quantitative and qualitative information on their perceptions of the uncertainty characterising our knowledge of the phenomena. The results indicate that there are competing interpretations of the cause-effect relationships leading to gene silencing (model structure uncertainty). In particular, the roles of post-transcriptional gene silencing, position effects, DNA-DNA interactions, direct-repeat DNA structures, recognition factors and dsRNA and aberrant zRNA are debated. The study highlights several sources of uncertainty beyond the statistical uncertainty commonly reported in risk assessment. The results also reveal a discrepancy between the way in which uncertainties would be prioritized on the basis of the uncertainty analysis conducted, and the way in which they would be prioritized on the basis of expert willingness to pay to eliminate uncertainty. The results also reveal a diversity of expert opinions on the uncertainty characterizing transgene silencing. Because the methodology used to diagnose uncertainties was successful in revealing a broad spectrum of uncertainties as well as a diversity of expert opinion, it is concluded that the methodology used could contribute to increasing transparency and fostering a critical discussion on uncertainty in the decision making process.
\end{abstract}

(c) 2007 Elsevier B.V. All rights reserved.

Abbreviations: DNA, Deoxyribonucleic acid; DCL, Dicer-like; DRM, de novo methyltransferase; dsRNA, Double-stranded RNA; mRNA, Messenger Ribonucleic Acid; miRNA, microRNAs; Pol, Polymerase; PTGS, post-transcriptional gene silencing; RISC, RNA-induced silencing complex; RDR, RNA dependent RNA polymerase; RNA, Ribonucleic acid; siRNA, Small interfering RNA; TGS, transcriptional gene silencing; T-DNA, transfer DNA.

* Corresponding author. Tel.: +45 39171473; fax: +45 39171878.

E-mail address: mak@euro.who.int (M.P. Krayer von Krauss). 


\section{Introduction}

Scientific uncertainty often becomes problematic when science is invested as a participant in the regulatory process, where political pressure and decision stakes can be high and values are often disputed (e.g. see Funtowicz and Ravetz (1990)). Proponents of potentially harmful activities often tend to use scientific uncertainty as an argument for postponing or waiving regulation (Michaels, 2005; Kaiser, 2005, 2003; UNESCO/COMEST, 2005). They demand certain knowledge about the harm caused, as well as about the cause-effect relationship leading to the harm, to justify the need for regulation. Strategic behaviour towards uncertainty is not only observed amongst defenders of business interests, but also among NGO's and other interest groups. While striving to ensure transparency and consistency in decision-making, regulators themselves often become trapped in a quest for certainty (van Asselt and Vos, 2005).

The inability of the policy community to deal with uncertainty is in part due to the fact that scientists often omit many important aspects of the uncertainty encountered when studying real-world problems. Scientists can make an important contribution to regulatory deliberations on the quality of the information available by making their uncertainties transparent. Information on uncertainty can be used to determine whether precautionary measures are warranted and to design adaptive policies. A central conclusion of the European Environmental Agencies report on the precautionary principle (Harremoës et al., 2001) is that there is little appreciation for the fact that science is characterised by more fundamental types of uncertainty than the statistical uncertainty commonly reported. Where non-statistical uncertainties are diagnosed, these often overshadow the statistical uncertainties in importance and should therefore be at the heart of the debate. This realisation has led to the development of a variety of new approaches aimed at helping experts communicate the full spectrum of uncertainty characterising their assessments. (e.g. Krayer von Krauss, 2005; Kloprogge et al., 2005; Kloprogge and van der Sluijs, 2002; Janssen et al., 2005; van der Sluijs et al., 2005, 2003; van Asselt, 2000; Risbey et al., 2005). These new approaches are however only beginning to be applied and much work remains to be done in view of developing methods to produce information about uncertainty that is useful for developing policy.

The goal of this article is to demonstrate, test and evaluate an approach to diagnosing, prioritising and communicating uncertainty in policy sciences. The approach builds on the methodology applied by Krayer von Krauss et al. (2004) on the case study of risk assessment of herbicide tolerant canola. After presenting the approach, we will illustrate how it was applied through interviews conducted during the spring of 2005. The goal of the interviews was to elicit expert knowledge on the uncertainty characterising a basic scientific problem: transgene silencing in genetically modified plants. The results of the interviews will be presented and discussed. But first, the case study of transgene silencing and the experts who participated in the study are introduced.

\section{Background on the case study}

In genetic engineering, alien genes, referred to as transgenes, are inserted into conventional plant species to create genetically modified plants. The level at which the transgene is expressed in the new plant (i.e., the transformant) is unpredictable and varies from one transformant to another. Sometimes the newly inserted transgenes are not expressed at all. This can be due to a phenomenon referred to as transgene silencing. Transgene silencing is an interesting phenomenon for several reasons. First, the mechanisms underlying transgene silencing are still not completely understood by scientists (Matzke et al., 2004; Schubert et al., 2004; Fagard and Vaucheret, 2000; De Block and Debrouwer, 1993), thereby highlighting the limitations in knowledge of how genes operate when they are placed into a new genome. Second, there are situations where transgene silencing can be unfortunate, e.g. in the case where, in order to avoid the transfer of transgenes via pollen spread, plants have been modified to make them sterile (Doerfler et al., 1997). In this case, silencing of the gene that causes sterility leads to the production of pollen, which could then lead to the unwanted spread of transgenes to wild or non-transgenic plants. Different levels of gene expression may disrupt the cell metabolism, hence causing changes in the functional properties of

Table 1 - Experts interviewed in this study

\begin{tabular}{|c|c|c|}
\hline Experts & Affiliation & Expertise \\
\hline 1 & $\begin{array}{l}\text { Matzke Lab, Gregor Mendel Institute for Molecular Plant } \\
\text { Biology, Austria }\end{array}$ & RNA silencing, epigenetics, DNA-methylation, Arabidopsis \\
\hline 2 & $\begin{array}{l}\text { Molecular Plant Virology Group, Institute of Botany, } \\
\text { University of Basel, Switzerland }\end{array}$ & Molecular biology, virology, biotechnology, plant research \\
\hline 3 & $\begin{array}{l}\text { Molecular Plant Virology Group, Institute of Botany, } \\
\text { University of Basel, Switzerland }\end{array}$ & Plant molecular biology, virology, silencing, epigenetics, biotechnology. \\
\hline 4 & $\begin{array}{l}\text { Institute of Cell and Molecular Biology, University of } \\
\text { Edinburgh, Scotland }\end{array}$ & $\begin{array}{l}\text { Transgene silencing, control of transgene expression, histone methylation, } \\
\text { gene regulation, plant development. }\end{array}$ \\
\hline 5 & $\begin{array}{l}\text { Laboratory of Phytopathology, Wageningen University, } \\
\text { The Netherlands }\end{array}$ & Plant pathology, Arabidopsis biochemistry, proteasis. \\
\hline \multicolumn{3}{|c|}{ NGO Representatives } \\
\hline 1 & EcoNexus, Brighton, United Kingdom & Plant biology, molecular biology, virology, genetics and RNA biology \\
\hline 2 & EcoNexus, Brighton, United Kingdom & Plant biology, plant molecular genetics, Arabidopsis \\
\hline
\end{tabular}


the organism (Inose and Murata, 1995). Potential secondary effects include changed levels of bioactive compounds in the organism and altered levels of antinutrients as well as potential allergens and toxins (Lappé et al., 1999; Novak and Haslberger, 2000). Under the EU legislation on the risk assessment of genetically modified organisms (2001/18/EC), gene silencing is considered a mechanism that can lead to the occurrence of adverse effects and the stability of the transgene should therefore be reported on in the approval process (2002/ 623/EC).

The goal of our interviews was to elicit expert knowledge on i) the conceptual model used by scientists to explain transgene silencing, and ii) information on the uncertainty characterising current scientific knowledge of the phenomena.

\section{Selection of experts}

The main criterion used to select the experts was their familiarity with the case study. All of the experts interviewed were either currently involved in research activities pertaining to transgene gene silencing, or had been within the recent past. Table 1 presents the affiliations of the experts interviewed as well as key words describing their area of expertise. Although some effort was made to examine an envelope of salient perspectives by drawing on expertise in both academia and industry, only researchers from academia responded to the invitation to participate in the study. Two representatives of a non-profit, public interest research organization were consulted informally in order to receive feedback on the study design and identify their concerns in relation to transcriptional gene silencing. Unfortunately, their level of expertise on the specific topic of transcriptional gene silencing was not sufficient for them to be considered "experts" in the context of this study.

\section{Methodology}

The methodology adopted in this study was very similar to the one presented in Krayer von Krauss et al. (2004). Each interview was conducted in four basic parts as follows:

i. Review of a proposed influence diagram (system model);

ii. Assessment of level and nature of uncertainty;

iii. Surprise analysis;

iv. Consistency test.

\subsection{Model locations and structure}

The first part of the interview focused on the locations dimension of uncertainty. The goal was to inventory the important model locations, as well as to identify disagreement regarding the model locations, in view of diagnosing model structure uncertainty. The experts were presented with an influence diagram (see Fig. 1) illustrating the cause-effect relationships scientist suspect are involved in transgene silencing. The diagram was developed by inferring on the basis of scientific journal articles, as well as with the assistance of an expert in the field.

Scientists distinguish between two different types of gene silencing: transcriptional gene silencing (TGS) and posttranscriptional gene silencing (PTGS). According tot he present understanding in the field, TGS results from the inactivation of the promoter (T-DNA), while PTGS occurs when the promoters are active and the genes transcribe, but the mRNAs fail to accumulate. In order to simplify the case study, the choice was made to focus mainly on TGS. However, as can be seen in Fig. 1, the two phenomena are related to oneanother and to some extent, one cannot avoid discussing PTGS, as scientist suspect that it may influence the occurrence

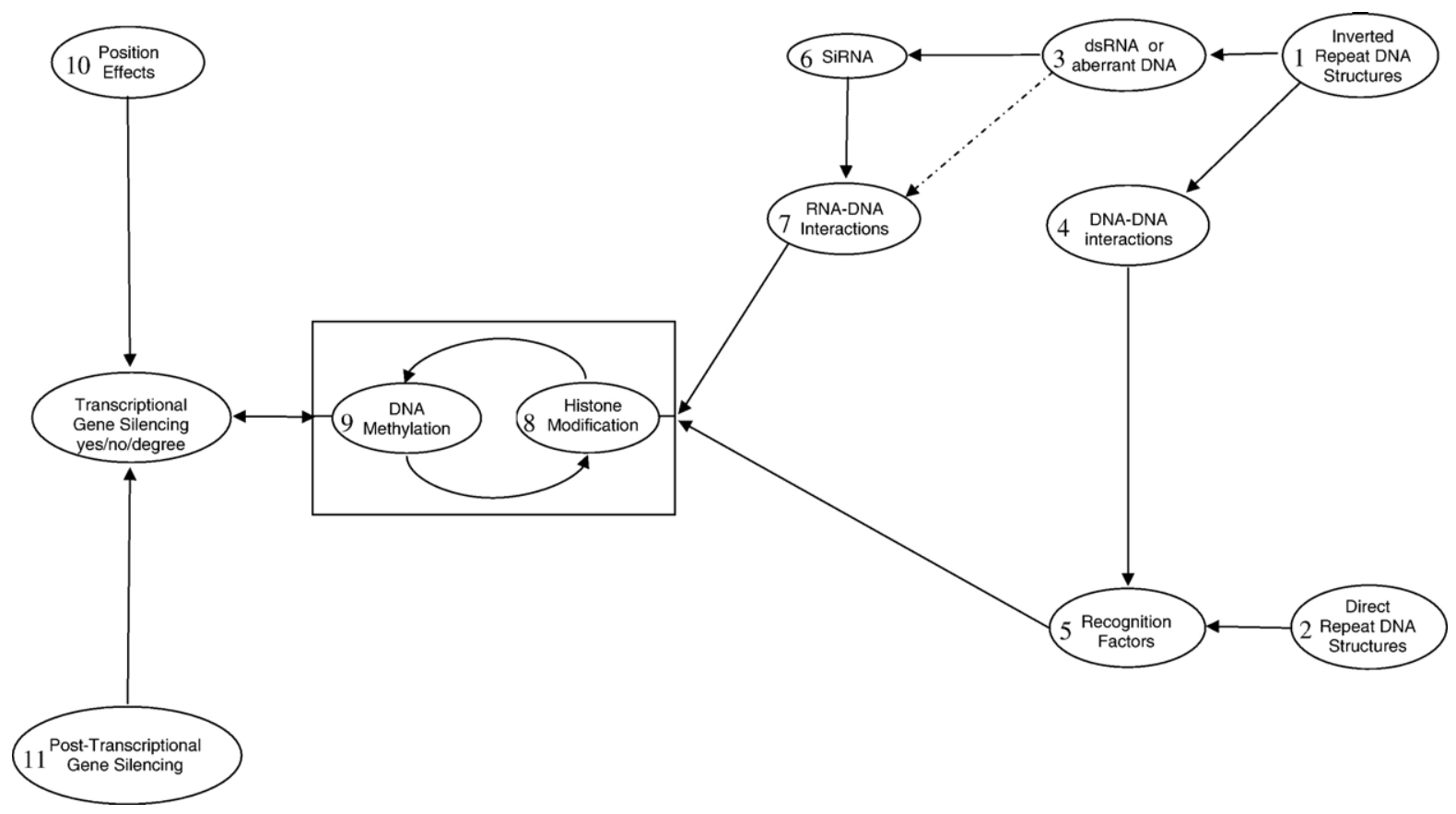

Fig. 1-Influence diagram illustrating the cause-effect relationships postulated to explain transcriptional transgene silencing. 
Box 1

Detailed explanation of the causal pathways leading to TGS

\section{Repeat-induced DNA methylation}

Transgenes which are inserted as an inverted repeat (Fig. 5, ellipse 1) or a direct repeat (ellipse 2) have a tendency to become inactivated. In the case of inverted repeat structures, transcription through the repeated region produces an RNA that is selfcomplimentary and can fold back on itself, thus providing a source of dsRNA (ellipse 3). This dsRNA and/or Dicer-produced siRNA products (ellipse 6) can act in trans on homologous DNA targets (RNA-DNA interactions; ellipse 7) as well as in cis to induce DNA methylation and chromatin modifications. A requirement for short RNAs and not dsRNA directly remains to be demonstrated conclusively. Alternatively, multicopy transgenes might express an excessive amount of mRNA that will contain a fraction of 'aberrant' RNA (with a so far unknown defect(s)) sufficient to trigger silencing.

It is suspected that DNA-DNA interactions (ellipse 4) may also have an influence in this pathway. Inverted repeat DNA (ellipse 1) might adopt an aberrant DNA structure, e.g. a cruciform structure caused by local intrastrand base pairing (ellipse 3b). This aberrant structure could be recognized by yet ill-defined recognition factors (ellipse 5), including chromatin modifying complexes, which results in the acquisition of DNA methylation as well as chromatin modifications at the inverted repeat DNA.

Transgenes inserted as direct repeats (ellipse 2) are generally at a higher risk of becoming silenced than single copy transgenes. By unintended antisense transcription of direct repeats - e.g. from flanking plant promoters - siRNA are produced (ellipse 6) which result in silencing via RNA-DNA interactions (ellipse 7). Compared to single copy sequences, direct repeats are postulated to have a superior ability to maintain a full spectrum of siRNAs, corresponding to their entire sequence length. Arrays of direct transgene repeats might further induce a local specialized structure of chromatin that is targeted by recognition factors (ellipse 5 ) and results in DNA and chromatin modifications.

The following model for the establishment and maintenance of transcriptional silencing via DNA methylation induced by RNA has been proposed (ellipse 9): Following establishment of the methylation pattern, DNA methyltransferases (DMTases) and chromatin factors are recruited to stabilize the silent state. Methylation is preserved through histone modifying activities (ellipse 8). When silencing is fully established, DNA methylation and histone modifications are maintained by a feedback mechanism between both modifications (arrows from ellipse 8 to 9 and from 9 to 8). Thus, in a mechanistically similar way, transcriptional silencing originally induced by DNA/DNA interactions and recognitions factors binding to direct repeats can also be envisioned to be maintained, once either DNA methylation or histone modifications have been induced. DNA methylation can be both a cause and a consequence of silencing (double arrow).

\section{Chromosomal environment of the transgene}

When a transgene integrates into a chromosomal region that is heavily methylated and/or repetitive, it is silenced (ellipse 10). This is thought to be an effect of spreading of a condensed state of chromatin. Condensation of repetitive regions and/or methylation of them is thought to de a defense against transposable genetic elements that are able to move and multiply in the genome. Foreign DNA may also be condensed/methylated by the same mechanism. Factors, which - in some documented cases - contribute to silencing due to position effects at the insertion sites of transgenes, are sharp changes of CG content at the insertions sites, presence of short repeats and vicinity to transposable elements. However, positions effects can also include the presence of insertion site-located regulatory elements, which might result in the unintended transcription of parts of the transgene, such as transgene-based promoters. Unintended transcription and thus production of aberrant RNA or antisense RNAs might result in the formation of siRNAs and silencing via RNA/DNA interactions.

\section{"Influence of Post-transcriptional gene silencing (ellipse 11)}

Transgene silencing can also be executed at the post-transcriptional level by RNAi-like mechanisms.

of TGS. Fig. 1 illustrates the three principle causal pathways scientists suspect lead to the occurrence of TGS:

- Repeat-induced DNA methylation;

- Chromosomal environment of the transgene;

- Influence of Post-transcriptional gene silencing (PTGS).

A more detailed explanation of these causal pathways is provided in Box 1. The diagram in Fig. 1 is intended to serve as a graphical representation of the causal pathways explained in Box 1, and not as the basis for a computable model.

The experts were asked to comment on whether the diagram mentioned all of the parameters and processes that they thought were key to understanding transcriptional gene silencing, and on whether the functional relationships between different parameters were accurately depicted. The goal of these questions was to identify any disagreements or alternative views on the causal structure represented in the diagram.

\subsection{Assessing the level and nature of uncertainty}

The second part of the interview focused on the level of uncertainty characterising each of the model locations illustrated in Fig. 1. In the investigation performed by Krayer von Krauss et al. (2004), the scale presented in Fig. 2 was used to assess the level of uncertainty. The scale, illustrated 


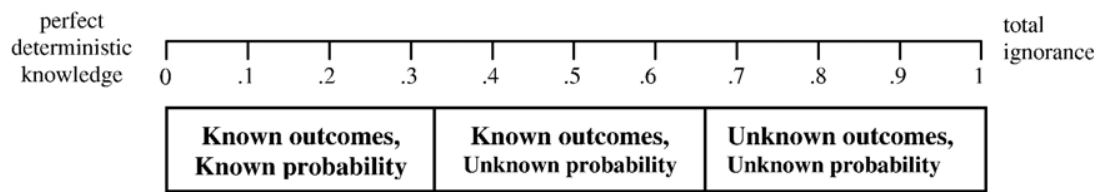

Fig. 2-The quantitative scale used by Krayer von Krauss et al. (2004) to assess the level of uncertainty (Source: Krayer von Krauss et al. (2004)).

in Fig. 2, was divided into three broad categories, consistent with the distinction made in the literature regarding different levels of uncertainty (see ESTO, 2001; Walker et al., 2003; Schneider and Turner, 1994; Faber et al., 1992; Smithson, 1988). One of the conclusions of Krayer von Krauss et al. (2004) was that the methodology could be refined by using generic descriptive formula to further characterize the terminology used to designate the different levels of uncertainty. On this basis, the set criteria presented in Table 2 were developed for the purpose of identifying the level of uncertainty. The use of criteria to evaluate knowledge quality is inspired by the NUSAP system for uncertainty assessment, which was proposed by Funtowicz and Ravetz (1990). In this method, quantitative information on uncertainty is complemented by qualitative information obtained on the basis of a systematic multi-criteria evaluation of the underpinning and scientific status of numbers ("pedigree"). The pedigree criteria were explained to the experts and they were asked to apply them to evaluate each component of Fig. 1. The level of uncertainty was determined on the basis of the scores obtained, according to the scale presented in Table 2. In this way, the level of uncertainty was assessed for: i) the structure of the overall model; ii) the structure of each of the three sub-models identified above; and iii) each of the individual components of the model (represented by ellipses in Fig. 1). Criteria 1, 2 and 3 were applied to evaluate model structure, while the fourth criterion was applied to evaluate individual model components.

In Table 2, the first two criteria distinguish between the level of theoretical understanding (to what degree do we know how the system works?) and the level of empirical information (to what degree do we have information describing the system?). With regards to model structure and model components, the evaluation scale ranges from a situation where we have a single well known structure/value, to a situation where we have a range of candidates which we can rank according to probability or according to plausibility, to a situation where we are unable to rank candidates or even identify them.

Experts were then asked to specify whether the uncertainty identified was predominantly due to natural variability in the phenomenon being observed (stochastic uncertainty), or if it was mainly due to deficiencies in expert knowledge or the methods available for studying the phenomenon (epistemic uncertainty).

The second part of the interview was ended by asking the experts to assess the sensitivity of the model to errors in the structure of the model, sub-model or model component, using the scale presented in Fig. 3. The scale is a slightly modified version of the scale used for this purpose by Krayer von Krauss

\section{Table 2 - Criteria for evaluation of the level of uncertainty}

\begin{tabular}{|c|c|c|c|c|c|}
\hline \multirow{2}{*}{$\begin{array}{l}\text { Level of } \\
\text { Uncertainty }\end{array}$} & \multirow{2}{*}{ Score } & \multicolumn{4}{|c|}{ Evaluation criteria } \\
\hline & & $\begin{array}{l}\text { 1. Level of theoretical } \\
\text { understanding }\end{array}$ & $\begin{array}{l}\text { 2. Level of } \\
\text { empirical } \\
\text { information }\end{array}$ & $\begin{array}{l}\text { 3. Ability to identify the } \\
\text { model structure }\end{array}$ & $\begin{array}{l}\text { 4. Ability to attribute a value } \\
\text { to the model component }\end{array}$ \\
\hline Determinism & 0 & $\begin{array}{l}\text { Perfect } \\
\text { understanding } \\
\text { of the system. }\end{array}$ & $\begin{array}{l}\text { Perfect information } \\
\text { on the system. }\end{array}$ & $\begin{array}{l}\text { We know exactly what the } \\
\text { model structure is. }\end{array}$ & $\begin{array}{l}\text { We know exactly what the } \\
\text { value will be. }\end{array}$ \\
\hline $\begin{array}{l}\text { Statistical } \\
\text { Uncertainty }\end{array}$ & 1 & $\begin{array}{l}\text { We know in great } \\
\text { detail how the } \\
\text { system works. }\end{array}$ & $\begin{array}{l}\text { We have a great } \\
\text { deal of information } \\
\text { on the entire system. }\end{array}$ & $\begin{array}{l}\text { We know the range of } \\
\text { possible candidate models and } \\
\text { their associated probabilities. }\end{array}$ & $\begin{array}{l}\text { We know the range of possible } \\
\text { values and their } \\
\text { associated probabilities. }\end{array}$ \\
\hline \multirow[t]{2}{*}{$\begin{array}{l}\text { Scenario } \\
\text { Uncertainty }\end{array}$} & 2 & $\begin{array}{l}\text { We understand } \\
\text { how the main } \\
\text { mechanisms of } \\
\text { the system work. }\end{array}$ & $\begin{array}{l}\text { We have a } \\
\text { considerable } \\
\text { amount of } \\
\text { information on } \\
\text { the system. }\end{array}$ & $\begin{array}{l}\text { We know the range of possible } \\
\text { candidate models and we are } \\
\text { able to rank them ordinally } \\
\text { based on plausibility. }\end{array}$ & $\begin{array}{l}\text { We know the range of possible } \\
\text { values and we are able to } \\
\text { rank them ordinally based } \\
\text { on plausibility. }\end{array}$ \\
\hline & 3 & $\begin{array}{l}\text { We only understand } \\
\text { parts of the system. }\end{array}$ & $\begin{array}{l}\text { We have some } \\
\text { information on } \\
\text { the system, but } \\
\text { it is limited. }\end{array}$ & $\begin{array}{l}\text { We know the range of possible } \\
\text { candidate models, but cannot } \\
\text { rank them. }\end{array}$ & $\begin{array}{l}\text { We know the range of possible } \\
\text { values, but cannot rank them. }\end{array}$ \\
\hline \multirow[t]{2}{*}{$\begin{array}{l}\text { Identified } \\
\text { Ignorance }\end{array}$} & 4 & $\begin{array}{l}\text { We have some clues } \\
\text { as to how the } \\
\text { system works. }\end{array}$ & $\begin{array}{l}\text { We have only very } \\
\text { little information on } \\
\text { the system. }\end{array}$ & $\begin{array}{l}\text { We can imagine some candidate } \\
\text { models, but it is likely there are } \\
\text { other model candidates of which } \\
\text { we are unaware. }\end{array}$ & $\begin{array}{l}\text { We can imagine some values, } \\
\text { but we don't know the bounds } \\
\text { of the range of possible values. }\end{array}$ \\
\hline & 5 & $\begin{array}{l}\text { We don't } \\
\text { understand the } \\
\text { system at all. }\end{array}$ & $\begin{array}{l}\text { We don't have any } \\
\text { information on } \\
\text { the system. }\end{array}$ & $\begin{array}{l}\text { We cannot imagine the } \\
\text { model structure. }\end{array}$ & $\begin{array}{l}\text { We cannot imagine the } \\
\text { values possible. }\end{array}$ \\
\hline
\end{tabular}




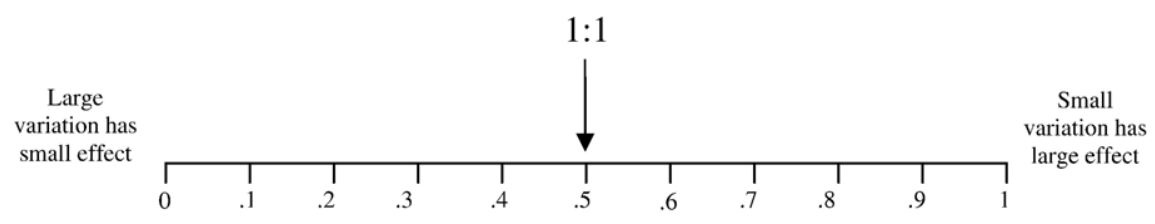

Fig. 3-Scale used to assess sensitivity.

et al. (2004). On the scale, a 0 implies that a large change in the element would have only a small effect on the conclusion, a 0.5 implies that a change would have a proportional effect, and a 1 implies that a small change would have a large effect. The scale was explained to the experts and they were asked to assess the sensitivity of the conclusion to changes in each of the key parameters and processes identified in the influence diagram. No guidance was given as to the interpretation of the terms "large" and "small", and the experts were therefore to make their own subjective judgment in this respect.

\subsection{Surprise analysis}

The third part of the interview was aimed at fostering a dialogue on issues that may have been left out of the assessment and potential surprises (i.e., context uncertainty), as well as on ignorance. Thus, the experts were asked questions aimed at identifying potential unanticipated or indirect effects associated to gene silencing. The experts were also presented with a scenario intended to help them reflect on potential surprises. The scenario question was as follows:

"Imagine you have been awarded a sizeable budget to conduct research into transgene silencing and conduct an extensive research program lasting several years. Can you think of a result of this research that would really surprise you?"

\subsection{Consistency test}

Finally, the interviews were ended with a test aimed at verifying how consistent the experts were in assessing the uncertainty level and the sensitivity associated with various elements of the influence diagram. Experts were given 100 poker chips and asked to allocate a fixed number of chips to each of the key elements of the influence diagram that they had assessed previously, to indicate how much they would be willing to invest to completely eliminate the uncertainty on that aspect of the influence diagram.

\section{Results and discussion}

\subsection{Model locations and structure}

The majority of the experts felt that the influence diagram presented in Fig. 1 represented the main processes and parameters describing transcriptional gene silencing. However, the interviews did reveal some areas where the experts disagreed on the structure of the model (i.e. how the components of the diagram are related to one another).
The areas of disagreement concerned the following components of the diagram:

- post-transcriptional gene silencing (ellipse 11);

- position effects (ellipse 10);

- DNA-DNA interactions (ellipse4);

- direct-repeat DNA structures (ellipse 2);

- recognition factors (ellipse 5).

- dsRNA and aberrant RNA (ellipse 3).

One of the experts interviewed felt that the influence of post-transcriptional silencing would be best represented by connecting PTGS (ellipse 11) to dsRNA/aberrant RNA (ellipse 3). The expert explained that siRNAs derived from transgenes is incorporated into the cytoplasmic effector complex RISC, which is targeted in sequence-dependent manner to homologous mRNA, resulting in its cleavage. According to the expert, published results indicate that transgenes subjected to posttranscriptional regulation can also be targeted for DNA methylation, suggesting that cytoplasmic and nuclear events may be linked via a common inducer, which is dsRNA (ellipse 3) and/or small RNAs (ellipse 6).

Another expert suggested that the influence of position effects (ellipse 10) and PTGS (ellipse 11) would be best illustrated by connecting these ellipses to the box illustrating histone modifications (ellipse 8) and DNA methylation (ellipse 9), rather than to the TGS ellipse. The expert explained that the possibility that position effects could influence TGS is only based on educated guesses, while there are firmly established findings that position effects play only a minor role. According to the expert, there are firmly established findings that TGS plays a major role in genome defence, e.g. transposon silencing, it is beyond reasonable doubt that this is correlated to histone modifications (ellipse 8) and DNA methylation (ellipse 9), and there is a clear showing that PTGS (ellipse 11) can cause DNA methylation (ellipse 9). According to the expert, although the potential association between PTGS (ellipse 11) and histone modification (ellipse 8 ) is only speculative at this point, it seems very likely.

One expert suggested that position effects (ellipse 10) should also be linked to SiRNA (ellipse 6). The expert explained that factors which can contribute to silencing due to position effects are sharp changes of CG content at the insertions sites, presence of short repeats and vicinity to transposable elements. However, positions effects can also include the presence of insertion sitelocated regulatory elements, which might result in the unintended transcription of parts of the transgene, such as transgene-based promoters. Unintended transcription and thus production of aberrant RNA or antisense RNAs (ellipse 3) might result in the formation of siRNAs (ellipse 6) and silencing via RNA/DNA interactions (ellipse 7). 
Table 3 - Results of the evaluation of level of uncertainty on model structure

\begin{tabular}{|c|c|c|c|c|c|}
\hline \multirow[t]{2}{*}{ Model Structure } & \multicolumn{4}{|c|}{ Evaluation scores elicited (0-5) } & \multirow{2}{*}{$\begin{array}{l}\text { Level of } \\
\text { uncertainty }\end{array}$} \\
\hline & $\begin{array}{l}\text { Level of theoretical } \\
\text { understanding }\end{array}$ & $\begin{array}{l}\text { Level of empirical } \\
\text { information }\end{array}$ & $\begin{array}{l}\text { Ability to identify the } \\
\text { model structure }\end{array}$ & $\begin{array}{l}\text { Overall } \\
\text { Strength }\end{array}$ & \\
\hline Overall Model & $2.3[0.8]$ & $2[0.6]$ & $1.9[0.8]$ & $2.1[0.8]$ & $\begin{array}{l}\text { Scenario } \\
\text { uncertainty }\end{array}$ \\
\hline $\begin{array}{l}\text { Repeat-induced DNA methylation } \\
\text { sub-model }\end{array}$ & $2.4[0.7]$ & $2.2[0.7]$ & $2.3[0.4]$ & $2.3[0.7]$ & $\begin{array}{l}\text { Scenario } \\
\text { uncertainty }\end{array}$ \\
\hline $\begin{array}{l}\text { Chromosomal environment of the } \\
\text { transgene sub-model }\end{array}$ & $1.8[0.7]$ & $2.3[0.9]$ & $1.8[1.4]$ & $2.0[1.0]$ & $\begin{array}{l}\text { Scenario } \\
\text { uncertainty }\end{array}$ \\
\hline PTGS sub-model & 2 [1.3] & $1.7[0.9]$ & $2[1.3]$ & $1.9[1.2]$ & $\begin{array}{l}\text { Scenario } \\
\text { uncertainty }\end{array}$ \\
\hline
\end{tabular}

Three experts suggested that direct-repeat DNA structures (ellipse 2) could possibly have an influence on dsRNA/aberrant RNAs (ellipse 3). They argued that to date, there is little evidence that direct-repeat DNA structures (ellipse 2) can cause TGS (caused by the structure itself), and therefore the possible links to dsRNA/aberrant RNA (ellipse 3) and recognition factors (ellipse 5) are merely based on educated guesses. One of these three experts indicated that direct-repeat DNA structures (ellipse 2) could also be related to DNA-DNA interactions (ellipse 4), in that it is conceivable that if direct repeat DNA structures influence TGS at all, DNA-DNA interactions occur. The same expert pointed out that the possibility that recognition factors (ellipse 5) play a role in inducing TGS is base on crude speculation. However, if they do play a role, it is likely that they also intervene in the relationship between RNA-DNA interactions (ellipse 7) and the histone modifications (ellipse 8) and DNA methylation (ellipse 9) box.

Two experts suggested that dsRNA and aberrant RNA (ellipse 3) should be represented individually by separate ellipses and that an arrow should emanate from the histone modifications (ellipse 8) and DNA methylation (ellipse 9) box and point to the aberrant RNA ellipse. The aberrant RNA ellipse should then be connected to the dsRNA, which would retain its current position in the diagram (ellipse 3). The experts explained that methylation at asymmetrical sites is believed to be maintained by de novo methyltransferases DRM1 and DRM2 guided by RNA signals, possibly siRNA (ellipse 6) or long dsRNA (ellipse 3). The RNA signals to maintain complete methylation pattern may be produced by a recently discovered, plant-specific RNA polymerase IV (Pol IV). It is speculated that Pol IV may specifically recognize methylated DNA as a template and transcribe it into aberrant RNA (ellipse 3a). This aberrant RNA might be converted to dsRNA (ellipse 3B) by RNA-dependent RNA polymerase (RDR2). The resulting dsRNA will be cleaved by Dicer (DCL3) into siRNAs that will target cognate DNA for de novo methylation (at both asymmetric and symmetric sites).

\subsection{Assessment of the level and nature of uncertainty}

Tables 3 and 4 present the results of the assessment of the level of uncertainty characterizing the influence diagram (Fig. 1), based on the pedigree criteria presented in Table 2. Only point estimates were elicited. In Table 3, the first column lists the sub-models presented in the diagram, and the next four columns show the experts' assessment of how well each of the sub-models scored on the various criteria. The fifth column shows the overall strength, a cross row ranking tool, calculated as the average of the scores for all criteria. In each column, the results are reported as an average of the responses received, followed by the standard deviation in brackets. In Table 4, the first column contains the individual model components assessed, while the next column shows the experts' assessment of how well the model components scored on the criterion used. Here again, results are reported as the average of responses received followed by the standard deviation in brackets. In both tables, the final column shows the level of uncertainty, determined by comparing the average overall strength to the scale shown in the first two columns of Table 2.

As can be seen in Table 3, the structure of the overall model presented in Fig. 1, as well as the structure of the sub-models, is characterized by scenario uncertainty. To a certain extent, this concords well with the fact that, as was illustrated by the disagreement revealed in the assessment of the completeness

Table 4-Results of the evaluation of level of uncertainty on model components

\begin{tabular}{|c|c|c|}
\hline $\begin{array}{l}\text { Specific } \\
\text { components } \\
\text { in diagram }\end{array}$ & $\begin{array}{l}\text { Ability to attribute a value to } \\
\text { the model component. (0-5) }\end{array}$ & $\begin{array}{c}\text { Level of } \\
\text { Uncertainty }\end{array}$ \\
\hline $\begin{array}{l}1 \text { - Inverted } \\
\text { repeat DNA } \\
\text { structures }\end{array}$ & 1 [1.0] & $\begin{array}{l}\text { Statistical } \\
\text { uncertainty }\end{array}$ \\
\hline $\begin{array}{l}2-\text { Direct repeat } \\
\text { DNA structures }\end{array}$ & $2.2[0.8]$ & $\begin{array}{l}\text { Scenario } \\
\text { uncertainty }\end{array}$ \\
\hline $\begin{array}{l}3 \text { - dsRNA or } \\
\text { aberrant RNA }\end{array}$ & 1 [1.1] & $\begin{array}{l}\text { Statistical } \\
\text { uncertainty }\end{array}$ \\
\hline $\begin{array}{l}4-\text { DNA-DNA } \\
\text { interactions }\end{array}$ & $3.7[0.6]$ & $\begin{array}{l}\text { Scenario } \\
\text { uncertainty }\end{array}$ \\
\hline $\begin{array}{l}5-\text { Recognition } \\
\text { factors }\end{array}$ & $3.8[0.4]$ & $\begin{array}{l}\text { Identified } \\
\text { ignorance }\end{array}$ \\
\hline 6-SiRNA & $1.4[1.4]$ & $\begin{array}{l}\text { Statistical } \\
\text { uncertainty }\end{array}$ \\
\hline $\begin{array}{l}7-\mathrm{RNA}-\mathrm{DNA} \\
\text { interactions }\end{array}$ & $2.2[0.7]$ & $\begin{array}{l}\text { Scenario } \\
\text { uncertainty }\end{array}$ \\
\hline $\begin{array}{l}8 \text { - Histone } \\
\text { modification }\end{array}$ & $1.6[1.2]$ & $\begin{array}{l}\text { Statistical } \\
\text { uncertainty }\end{array}$ \\
\hline $\begin{array}{l}9-\text { DNA } \\
\text { methylation }\end{array}$ & $1[0.6]$ & $\begin{array}{l}\text { Statistical } \\
\text { uncertainty }\end{array}$ \\
\hline
\end{tabular}


Level, Sensitivity, and Influence of Uncertainty

Repeat-induced DNA methylation sub-model

Chromosomal environment of the transgene sub-model

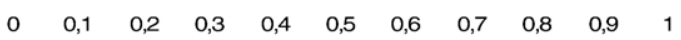

Overall model
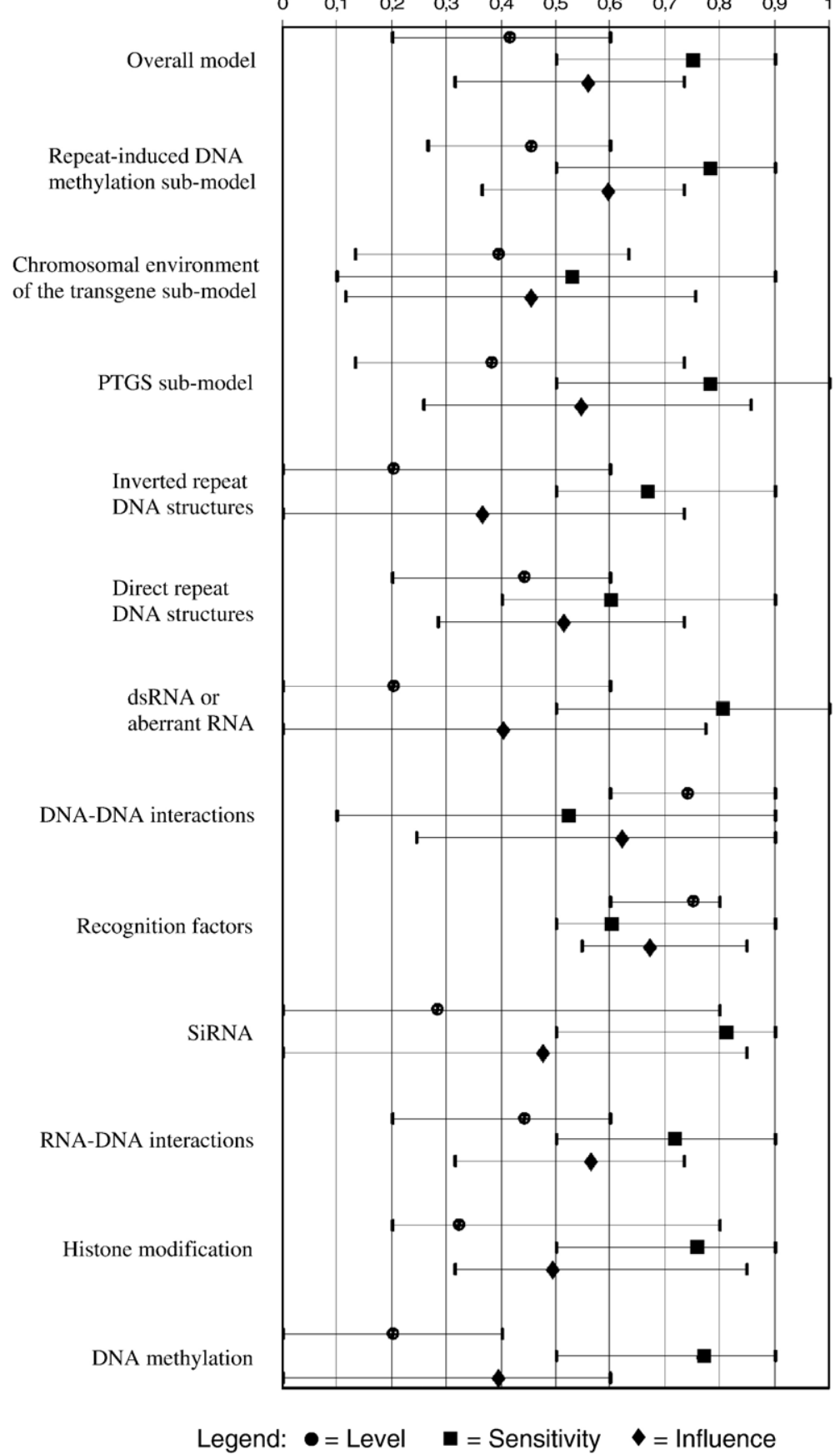

Fig. 4-Results of assessment of the relative level, the sensitivity, and the influence of uncertainty $\left(I=(L / 5 \times S)^{1 / 2}\right)$. Only point estimates were elicited. Solid symbols denote the average of the individual point estimates obtained. They are bounded on the left by the lowest, and on the right by the highest, values elicited.

and structure of the influence diagram, there are competing scientific interpretations of the mechanisms leading to transcriptional gene silencing. Given the comment made by one expert in the first part of the interview, to the effect that the possibility that position effects could influence TGS is only based on educated guesses, one may have expected that the model structure of the chromosomal environment sub-model would be judged more uncertain than other sub-models. This is not reflected in the results.

The results presented in Table 4 indicate that two model components, DNA-DNA interactions and recognition factors, are characterized by a high level of uncertainty. This concurs with the comments made by some of the experts during the assessment of the completeness of the influence diagram. 
Table 5 - Results of assessment of nature of uncertainty

Element of influence diagram $\quad$ Nature of uncertainty

\begin{tabular}{lll}
\hline $\begin{array}{l}\text { Overall model } \\
\text { Repeat-induced DNA methylation }\end{array}$ & 2 & 3 \\
$\begin{array}{l}\text { sub-model } \\
\text { Chromosomal environment of }\end{array}$ & 2 & 3 \\
the transgene sub-model & 2 & 3 \\
PTGS sub-model & 1 & 3 \\
Inverted repeat DNA structures & 1 & 4 \\
Direct Repeat DNA structures & 4 & 4 \\
dsRNA or aberrant RNA & 1 & 1 \\
DNA-DNA interactions & 0 & 4 \\
Recognition factors & 3 & 4 \\
SiRNA & 2 & 2 \\
RNA-DNA interactions & 3 & 3 \\
Histone modification & 3 & 2 \\
DNA methylation & 2
\end{tabular}

Displayed is the number of experts attributing a given Nature to a given model Location.

There will always be a plurality of perspectives on uncertainty, and uncertainty assessment can only aspire to make this transparent. Thus, the relative value of the approach presented in this article should be evaluated in terms of the extent to which it helped make a broad spectrum of uncertainties, and the plurality of perspectives on uncertainty, transparent.

It is interesting to note from the standard deviations reported that there seems to be significant disagreement amongst experts, for example regarding the PTGS sub-models (Table 3) or the SiRNA model component (Table 4). All in all, the results display a much richer diversity of expert opinion than the consensus documents typically published by regulatory authorities. This is consistent with the observations made in other expert elicitation studies (Krayer von Krauss et al., 2004; Morgan et al., 2001; Morgan and Keith, 1995; Stirling and Mayer, 2001). In many cases, the documents published by regulatory authorities are written in such a way that they mask the diversity of expert opinions. Moreover, because this form of "one-way" communication (i.e., where the intended audience does not participate) is necessarily constrained by the limited spectrum of symbolic resources available for written communication, it often masks the diversity of perceptions associated with words such as "likely", "uncertainty" and "ignorance". Thus, while the impression of a consensus may be conveyed, reality is such that each of the experts contributing to a given assessment, and each of the policy makers and stakeholders reading it, may have a different interpretation of the message communicated in the document. This has been demonstrated well by empirical research into risk communication and experience in practice (Patt and Schrag, 2003; Patt and Dessai, 2005; Morgan, 1998; Wallsten et al., 1986).

Fig. 4 shows the results of the assessment of the relative level of uncertainty, the assessment of the sensitivity of the model to errors in the structure of the overall model, submodels or model components (Fig. 1), as well as the "influence" of the uncertainty identified. The relative level of uncertainty was calculated by dividing the overall strength presented in Table 3, and the min, max and mean score presented in Table 4, by the maximum achievable score (i.e., divided by 5). The influence of the uncertainty was calculated by taking the square root of the product of the relative level of uncertainty and the sensitivity $\left(I=\left(L_{/ 5} \times S\right)^{1 / 2}\right)$. This approach is evolved out of a pragmatic desire to represent all of the results on a 0 to 1 scale, rather than by reference to a solid theoretical foundation. In the figure, solid symbols denote the average of the individual point estimates obtained. They are bounded on the left by the lowest, and on the right by the highest, values elicited.

Table 5 presents the results of the assessment of the nature of uncertainty. Here, stochastic uncertainty is uncertainty due to the inherent variability of the phenomena under consideration, and epistemic uncertainty is due to limitations in our knowledge. The values shown in the Table indicate the number of experts that thought that the uncertainty they had identified was predominantly due to the type of uncertainty in question (stochastic or epistemic uncertainty). The results suggest that it could be possible to reduce uncertainty by conducting additional research into the model components Inverted repeat DNA structures, Direct Repeat DNA structures, DNA-DNA interactions, and Recognition factors. Conversely, as the uncertainty characterizing the model component dsRNA or aberrant RNA is dominated by natural variability, it is unlikely that it can be reduced much further by conducting additional research. Not all rows sum to 5 due to the fact that one expert preferred not to express himself on Recognition factors, considering this outside of his field of expertise.

\subsection{Consistency test}

Fig. 5 illustrates the results of the consistency tests, in the form of an index of uncertainty influence versus the willingness to pay to eliminate uncertainty. Willingness to pay is based on the number of poker chips the experts were willing to
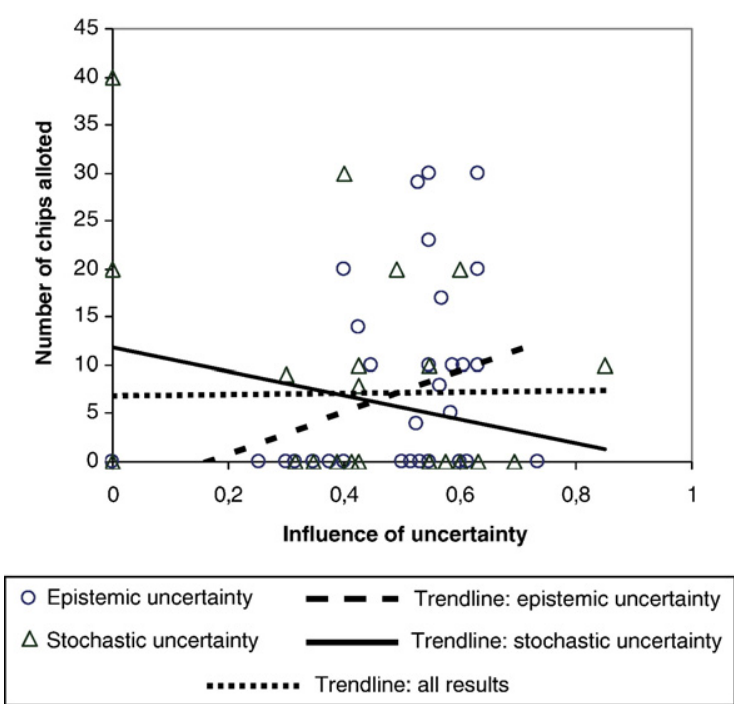

Fig. 5-Consistency index between the influence of uncertainty and the willingness to pay to eliminate uncertainty. 
"invest" into research on a particular component of the influence diagram in order to completely eliminate the uncertainty on that component. One hundred chips were given to the experts to apportion among research needs.

As was explained in the methodology, the experts were asked to invest their chips according to how much they would be willing to invest to completely eliminate the uncertainty each aspect of the influence diagram. Consistency is interpreted here as the degree to which the willingness of experts to pay to eliminate uncertainty at a given model location correlated with their response on the "Level", "Sensitivity" and "Nature" of uncertainty for that location. Thus, a consistent expert would be expected to allot more chips to model locations on which or she deemed the influence of uncertainty to be large (i.e., high levels of uncertainty and sensitivity), and for which he or she the uncertainty to be predominantly of an epistemic nature.

In Fig. 5, the dotted trendline indicates the trend in how experts invested their chips on model components they thought were dominated by epistemic uncertainty. The solid trendline indicates the trend in how experts invested their chips on model components they thought were dominated by stochastic uncertainty. As can be seen in the figure, apart from the trendline indicating that experts would be willing to invest increasing amounts of resources as the influence of epistemic uncertainty increases, consistency was not a prominent feature of the responses given by the experts.

This apparent lack of consistency can be interpreted in different ways. To a certain extent, it could be an indication that the experts who participated in the study did not fully grasp the concepts they were presented with. However, given the many factors that could influence experts willingness to pay (e.g. personal interests and biases), it is not possible to conclude that a lack of understanding is the basis for the inconsistency displayed.

Although it is only possible to speculate on the causes of the inconsistency observed, documenting the inconsistency remains an important observation. An important objective of uncertainty analyses such as the one presented here is to prioritize sources of uncertainty. The results demonstrate that a prioritization of uncertainties based on an uncertainty analysis such as ours can yield results that are quite different from those obtained when prioritizing on the basis of experts willingness to pay to eliminate uncertainty. Expert ranking based on willingness to pay could be biased by scientific curiosity, which does not necessarily correspond to a ranking based on the relevance for policy. The approach presented here provides an alternative ranking tool to rankings based on willingness to pay or analyses of the value of additional information.

To investigate the causes of the inconsistencies noted above, future studies may include an extra feedback loop where experts are questioned on the discrepancy between the results of the uncertainty analysis and their own willingness to pay to eliminate uncertainty.

The inconsistencies revealed here may lead some to question the usefulness of investing the efforts required to perform uncertainty analyses according to the approach proposed in the current study. However, it is important to recall another important goal of performing such analyses, which is to provide substance to a deliberative decision making process, in view of fostering reflexivity. Within a deliberative policy making process, the interpretive flexibility offered by qualitative descriptors of uncertainty is not necessarily a negative thing. Although the use of relative terminology such as "considerable", "good/bad", "likely", "uncertain" and "ignorance" may be a source of ambiguity, it also forces stakeholders to deliberate on the meaning of these terms, and can thereby help bridge the diversity of positions and framings held by the various actors involved (Schackley and Wynne, 1997; Star and Griesemer, 1989; Eisenberg, 1984). It is through the deliberations generated by the disagreements and uncertainties made obvious by the uncertainty analysis that the different actors of the policy process become more reflexive, and take decisions that account for uncertainties.

\subsection{Surprise analysis}

Many of the experts interviewed indicated that scientists' knowledge of the mechanisms leading to transcriptional gene silencing is rapidly evolving and that they would therefore expect surprise discoveries to take place in the future.

One expert mentioned that he would be surprised to observe a situation where all of the RNA components necessary for repeat-induced DNA methylation to take place were present, but silencing does not occur, possibly indicating that environmental conditions exercise an influence on this pathway.

The NGO representatives put forth the following scenario as a possible biosafety risk related to gene silencing:

"In order to engineer resistance to a target virus, a viral gene can be inserted into a plant. If this gene becomes silenced the plant will be resistant to the virus. When a virus enters the plant this silencing effect transfers to the virus- thus preventing infection. In this situation gene silencing is used deliberately to induce virus resistance, even though not all transformants carrying the gene will be resistant to the virus.

Safety tests on the crop are done on an uninfected plant in which silencing is active, thus little or no transgenic viral protein is being produced by the plant. If transgene silencing were unstable, then the viral gene would be expressed at a higher (probably much higher) level and one could argue that safety tests (e.g. compositional analysis) would no longer be valid.

Secondly, elevated expression of a virus gene may itself constitute a health hazard. Viral genes inserted into plants are usually considered safe because the protein is expressed at a low level. Low level expression of the transgene protein would no longer be a property of the crop if silencing was instable /inactivated."

While the focus of this study has been on the scenario whereby a transgene intended to be expressed is accidentally/ unexplainably silenced, the above scenario represents the inverse situation, whereby the intention is that the transgene be silenced, but this accidentally/unexplainably fails.

Two experts were questioned on the plausibility of the above scenario, and on whether it could be argued that, if scientific knowledge is limited to the extent that silencing 
cannot always be explained, then, conversely, it was not possible to predict the failure of intentional silencing in all cases.

The experts judged the scenario to be plausible. Due to the many biotic and abiotic factors that can lead to suppression of silencing, it is not possible to predict whether silencing will be stable in all cases. However, the experts questioned the extent to which the expression of high levels of viral proteins could be considered as a health risk. They felt that if so, many of the conventional fruits and vegetables sold in supermarkets would have to be considered hazardous as they likely contain high levels of different viruses.

\section{Conclusion}

The results of this study indicate that there are competing interpretations of the cause-effect relationships leading to gene silencing (model structure uncertainty). In particular, the roles of post-transcriptional gene silencing, position effects, DNA-DNA interactions, direct-repeat DNA structures, recognition factors and dsRNA and aberrant RNA are debated.

The study highlights several sources of uncertainty at levels above and beyond the statistical uncertainty commonly reported on. The results show that the model components "DNA-DNA interactions" and "Recognition factors" are characterized by particularly high levels of uncertainty and that the conclusion of the model is quite sensitive to variations in these model components. As a large majority of the experts interviewed agreed that the uncertainty characterising these model components is predominantly epistemic in nature, it would seem appropriate to conduct further research on these components.

The consistency test conducted revealed a discrepancy between the way in which uncertainties would be prioritized on the basis of the uncertainty analysis we conducted, and the way in which they would be prioritized on the basis of experts willingness to pay to eliminate uncertainty. This is an important observation, due to the fact that an important objective of uncertainty analyses is to prioritize sources of uncertainty. Prioritizing uncertainties on the basis of our approach can yield results that are potentially more relevant to policy making than prioritizations based on experts willingness to pay to eliminate uncertainty. The approach presented here provides an alternative ranking tool to rankings based on willingness to pay or analyses of the value of additional information.

The results of the study make explicit a diversity of expert perceptions of the uncertainty characterising transgene silencing. This finding adds to the observations made in other expert elicitation studies, which indicate that there often exists a much richer diversity of expert opinion than that which is suggested by the consensus documents typically published by regulatory authorities.

All and all, the approach used successfully engaged experts in a dialogue that stimulated them to systematically reflect upon a broad spectrum of uncertainties. The experts identified levels of uncertainty above and beyond statistical uncertainty, and a large diversity of expert opinion was revealed. On this basis, it seems reasonable to conclude that the approach applied here contributed to making a broad spectrum of uncertainties, as well as a plurality of perspectives on uncertainty, transparent. The approach could help foster a critical, reflexive discussion on uncertainty. In the policymaking context, the information generated would contribute to deliberations on the quality of the information supporting decisions, on the extent of the precautionary measures warranted, and on the design of adaptive policies.

\section{Acknowledgements}

The authors would like to acknowledge the kind assistance of Prof. Reidunn B. Aalen of the Department of Molecular Biosciences, and Prof. Odd Arne Rognli of the Department of Plant and Environmental Sciences, Norwegian University of Life Science, University of Oslo in developing the influence diagram presented in the paper. We are also very grateful for the participation of the 7 anonymous experts in the study. This paper is a partial result of a larger project, entitled "Governance in the Field of Biotechnology and Operationalising the Precautionary Principle" (2002-2005). We gratefully acknowledge funding from The Research Council of Norway, project number 157207/S10. The principal investigators of this project were Carlo Aall (Vestlandsforskning, Sogndal) and Matthias Kaiser (NENT).

\section{R E F E R E N C E S}

2001/18/EC. Directive of the European Parliament and of the Council on the deliberate release into the environment of genetically modified organisms.

2002/623/EC. COMMISSION DECISION of 24 July 2002, establishing guidance notes supplementing Annex II to Directive 2001/18/ EC of the European Parliament and of the Council on the deliberate release into the environment of genetically modified organisms.

De Block M, Debrouwer D. Engineered fertility control in transgenic Brassica napus L.: histochemical analysis of another development. Planta (Heidelberg) 1993;189:218-25.

Doerfler W, Schubert R, Heller H, Kamner C, Hilger-Eversheim K, Knoblauch MR. Integration of foreign DNA and its consequences in mammalian systems. TIBTECH 1997;15:297-301.

Eisenberg EM. Ambiguity as strategy in organizational communication. Communication monographs, vol. 51; 1984.

ESTO. On science and precaution in the management of technological risk. In: Stirling A, editor. European Commission Joint Research Centre and European Science and Technology Observatory; 2001. EUR 19056/EN/2.

Faber M, Manstetten R, Proops J. Humankind and the environment: an anatomy of surprise and ignorance. Environ Values 1992;1:217-42.

Fagard M, Vaucheret H. (Trans)gene silencing in plants: how many mechanisms? Annu Rev Plant Physiol Plant Mol Biol 2000;51:167-94.

Funtowicz SO, Ravetz JR. Uncertainty and quality in science for policy. Dordrecht, NL: Kluwer Academic Publishers; 1990.

Harremoës P, Gee D, MacGarvin M, Stirling A, Keys J, Wynne B, et al., editors. The precautionary principle in the 20th century. Late lessons from early warnings. London, GB: Earthscan Publications Ltd.; 2001. 
Inose T, Murata K. Enhanced accumulation of toxic compound in yeast cells having high glycolytic activity: a case study on the safety of genetically engineered yeast. Int J Food Sci Technol 1995;30:141-6.

Janssen PHM, Petersen AC, van der Sluijs JP, Risbey J, Ravetz JR. A guidance for assessing and communicating uncertainties. Water Sci Technol 2005;52(6):125-31.

Kaiser M. Ethics, science, and precaution - A viewpoint from Norway. In: Tickner Joel, editor. Precaution, Environmental Science, and Preventive Public Policy. Washington DC: Island Press; 2003.

Kaiser M. Uncertainty and precaution 1: Certainty and uncertainty in science. In: Landeweerd L, Houdebine L-M, Termeulen R, editors. Bio technology-ethics - An introduction. Firenze: Angelo Pontecorboli Editore; 2005.

Kloprogge P, van der Sluijs JP. Choice processes in modelling for policy support, in: integrated assessment and decision support. In: Jakeman A, Rizzoli A, editors. Proceedings of IEMSS 2002 Conference, 24-27 June 2002, Lugano, Switzerland; 2002. p. 96-102. http://www.iemss.org/iemss2002/proceedings/ pdf/volume\%20uno/169_kloprogge.pdf.

Kloprogge P, van der Sluijs JP, Petersen A. 2005. A method for the analysis of assumptions in assessments: Exploring the value-ladenness of two indicators in the Fifth Dutch Environmental Outlook report commissioned by: Netherlands Environmental Assessment Agency (MNP), report published by: Netherlands Environmental Assessment Agency (MNP), Bilthoven and Unit Science, Technology and Society, Copernicus Institute, Utrecht University, Utrecht, the Netherlands, December 2005, 69 pp. http://www.rivm.nl/ bibliotheek/rapporten/550002010.pdf.

Krayer von Krauss MP. 2005. Uncertainty in policy relevant sciences. PhD Thesis, Institute of Environment and Resources, Technical University of Denmark. ISBN 87-89220-97-8.

Krayer von Krauss MP, Casman EA, Small MJ. Elicitation of expert judgments of uncertainty in the risk assessment of herbicide tolerant oilseed crops. J Risk Anal 2004;24(6):1515-27.

Lappé MA, Bailey EB, Childress C, Setchell KDR. Alterations in clinically important phytoestrogens in genetically modified, herbicide tolerant soybeans. J Med Food 1999;1:241-5.

Matzke M, Aufsatz W, Kanno T, Daxinger L, Papp I, Mette MF, et al. Genetic analysis of RNA-mediated transcriptional gene silencing. Biochim Biophys Acta 2004;1677:129-41.

Michaels D. Manufacturing uncertainty: contested science and the protection of the public's health and environment. Am J Public Health 2005;95:39-48.

Morgan GM. Uncertainty analysis in risk assessment. Hum Ecol Risk Assess 1998;4(1):25-39.

Morgan GM, Keith D. Subjective judgments by climate experts. Environ Sci Technol 1995;19:662-7.

Morgan GM, Pitelka LF, Shevliakova E. Elicitation of expert judgments of climate change impacts on ecosystems. Clim Change 2001;49:279-307.

Novak WK, Haslberger AG. Substantial Equivalence of Antinutrients and Inherent Plant Toxins in Genetically Modified Novel Foods. Food Chem Toxicol 2000;38:473-83.
Patt A, Dessai S. Communicating uncertainty: lessons learned and suggestions for climate change assessment. Comptes Rendus Geosci 2005;337:425-41.

Patt AG, Schrag D. Using specific language to describe risk and probability. Clim Change 2003;61:17-30.

Risbey J, van der Sluijs JP, Kloprogge P, Ravetz J, Funtowicz S, Corral Quintana S. Application of a checklist for quality assistance in environmental modelling to an energy model. Environ Model Assess 2005;10(1):63-79.

Schackley S, Wynne B. Global warming potentials: ambiguity or precision as an aid to policy? Clim Res 1997;8:89-106.

Schneider S, Turner BL. Anticipating global change surprise. In: Hassol SJ, Katzenberger J, editors. Elements of Change. Aspen Global Change Institute; 1994.

Schubert D, Lechtenberg B, Forsbach A, Gils M, Bahadur S, Schmidt R. Silencing in Arabidopsis T-DNA transformants: the predominant role of a gene-specific RNA sensing mechanism versus position effects. Plant Cell 2004;16:2561-72.

Smithson M. Ignorance and Uncertainty - Emerging Paradigms. Springer-Verlag. ISBN 3-540-96945-4; 1988.

Star SL, Griesemer JR. Institutional ecology, "translations" and boundary objects: amateurs and professionals in Berkeley's museum of vertebrate zoology, 1907-39. Soc Stud Sci 1989;19:387-420.

Stirling A, Mayer S. A novel approach to the appraisal of technological risk. Environ Plann C Gov Policy 2001;19:529-55.

UNESCO/COMEST. 2005. The Precautionary Principle, A report of an ad hoc working group, endorsed by COMEST /UNESCO April 2005 (members of the expert group: M. Kaiser (chair), J.v.d. Sluijs (rapporteur), S. Beder, V. Hösle, A. Kemelmajer de Calucci, A. Kinzig; UNESCO secretariat: H. t. Have, S. Scholze, E. Kuok), UNESCO: Paris; also available on: http://unesdoc. unesco.org/images/0013/001395/139578e.pdf.

van Asselt MBA. Perspectives on uncertainty and risk. Dordrecht, NL: Kluwer Academic Publishers; 2000.

van Asselt MBA, Vos E. The precautionary principle in times of intermingled uncertainty and risk: some regulatory complexities. Water Sci Technol 2005;52(6):35-41.

van der Sluijs JP, Risbey J, Kloprogge P, Ravetz J, Funtowicz S, Corral Quintana S, et al. RIVM/MNP Guidance for uncertainty assessment and communication: detailed guidance. Utrecht University; 2003. http://www.nusap.net/downloads/detailedguidance.pdf $<$ https://webmail.euro.who.int/exchweb/bin/redir.asp? URL=http://www.nusap.net/downloads/detailedguidance.pdf $>$.

van der Sluijs JP, Craye M, Funtowicz S, Kloprogge P, Ravetz J, Risbey J. Combining quantitative and qualitative measures of uncertainty in model based environmental assessment: the NUSAP System. Risk Anal 2005;25(2):481-92.

Walker W, Harremoës P, Rotmans J, Van der Sluijs J, Van Asselt MBA, Jansen P, et al. Defining uncertainty: a conceptual basis for uncertainty management in model-based decision support. J Integr Assess 2003;4(1):5-17.

Wallsten TS, Budescu DV, Rapoport A, Zwick R, Forsyth B. Measuring vague meanings of probability terms. J Exp Psychol Gen 1986;155(4):348-65. 